\title{
A surgical treatment for frank rupture of acute type A small intramural hematoma
}

\author{
Daisuke Ueda ${ }^{1}$, Kosuke Niwa ${ }^{1}$, Hiroshi Nishikawa ${ }^{1}$, Yasuaki Tsuchida ${ }^{1}$, and Keigo \\ Yamashita $^{1}$ \\ ${ }^{1}$ Iseikai Hospital
}

February 11, 2022

\begin{abstract}
A 71-year-old woman was admitted to the hospital due to cardiac tamponade. Computed tomography revealed that the diameter and wall thickness of the ascending aorta was $36 \mathrm{~mm}$ and $9 \mathrm{~mm}$, respectively. An emergency surgery was performed uneventfully. The pathological findings indicated frank rupture of intramural hematoma.
\end{abstract}

\section{A surgical treatment for frank rupture of acute type A small intramural hematoma}

Daisuke Ueda, $\mathrm{MD}^{1)}$, Kosuke Niwa, $\mathrm{MD}^{1)}$, Hiroshi Nishikawa, MD ${ }^{1)}$, Yasuaki Tsuchida, $\mathrm{MD}^{2)}$, and Keigo Yamashita, $\mathrm{MD}^{1)}$

Department of Cardiovascular Surgery, Iseikai Hospital, 6-2-25 Sugahara, Higashiyodogawa-ku, Osaka, 5330022, Japan

Department of Pathology, Iseikai Hospital, 6-2-25 Sugahara, Higashiyodogawa-ku, Osaka, 533-0022, Japan

Corresponding author: Keigo Yamashita, MD, Department of Cardiovascular Surgery, Iseikai Hospital, 6-2-25 Sugahara, Higashiyodogawa-ku, Osaka, 533-0022, Japan. Telephone: +81-6-6326-1121; Fax: +81-66329-6111; E-mail: ke-igo@umin.ac.jp

\section{Data Availability Statement}

All relevant data are within the manuscript and its Supporting Information files.

\section{Conflicts of interest statement}

Authors declare no conflict of interest.

Written informed consent was obtained from the patient to publish this report in accordance with the journal's patient consent policy

\begin{abstract}
A 71-year-old woman was admitted to the hospital due to cardiac tamponade. Computed tomography revealed that the diameter and wall thickness of the ascending aorta was $36 \mathrm{~mm}$ and $9 \mathrm{~mm}$, respectively. An emergency surgery was performed uneventfully. The pathological findings indicated frank rupture of intramural hematoma.
\end{abstract}

\section{Key Clinical Message}

Acute type A small intramural hematoma should be aware of fatal complications. 
The treatment of acute type A intramural hematoma (IMH) has been controversial. It is reported that initial medical treatment with blood pressure and pain control and repetitive imaging may be a reasonable option, particularly in the absence of aortic dilation $(<50 \mathrm{~mm})$ and IMH thickness $<11 \mathrm{~mm}^{1)}$. A 71-year-old woman was admitted to the hospital due to cardiac tamponade. Computed tomography revealed that the diameter and wall thickness of the ascending aorta was $36 \mathrm{~mm}$ and $9 \mathrm{~mm}$, respectively, indicating type A intramural hematoma [Fig. (A, B)]. An emergency surgery was performed, but it resulted in uneventful outcomes [Fig. $(\mathrm{C}, \mathrm{D}, \mathrm{E})]$. The pathological findings indicated frank rupture of intramural hematoma [Fig. (F)]. Acute type A small IMH is rare; however, physicians should be aware of this possible complication.

\section{REFERENCES}

Erbel R, Aboyans V, Boileau C, et al. 2014. ESC Guidelines on the diagnosis and treatment of aortic diseases: Document covering acute and chronic aortic diseases of the thoracic and abdominal aorta of the adult. The Task Force for the Diagnosis and Treatment of Aortic Diseases of the European Society of Cardiology (ESC). Eur Heart J 35: 2873-2926.

\section{FIGURE LEGENDS}

Figure. Preoperative computed tomographic image (A)(B). Intraoperative image (C)(D)(E). Pathological image $(\mathrm{F})$.
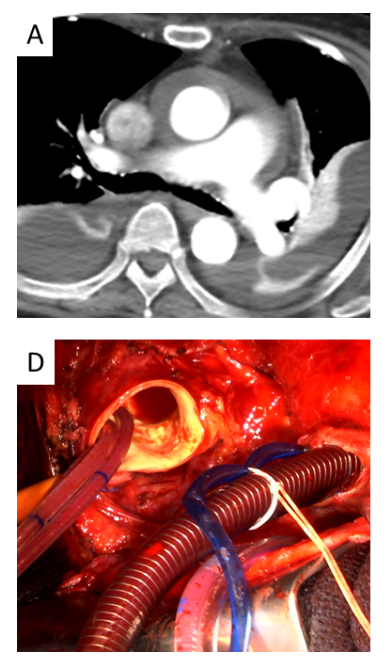
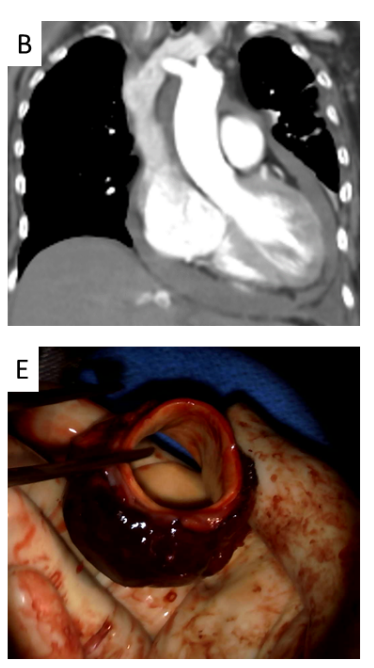
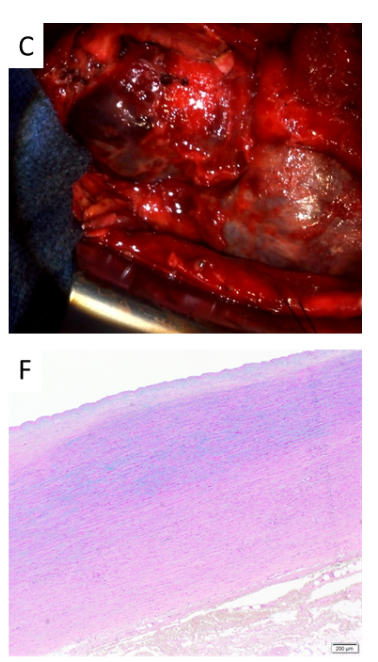